\title{
Educação dos sentidos na contemporaneidade e suas implicações pedagógicas
}

\author{
Luiza Silva Rodrigues*, Odilon José Roble* * \\ http://dx.doi.org/10.1590/0103-7307201507810
}

\section{Resumo}

Este texto aborda a "educação dos sentidos", temática atual, porém pouco explorada sistematicamente. Embora constituam a principal forma de apreensão do mundo, segundo Michel Onfray, e recebam, como afirma Christoph Türcke, uma espécie de "superestimulação" na sociedade da informação, os sentidos, paradoxalmente, são direcionados a objetos e interesses específicos, quase sempre ligados ao consumo. A proposta deste estudo situou-se na reflexão sobre corpo e sensibilidade, a partir do cruzamento entre essa razão dos sentidos e a lógica atual da superestimulação. Encontra-se a premência de um saber estético, que não apenas se direciona à arte, mas se espraia para * Faculdade de Educação Física, Universidade Estadual de Campinas, Campinas, SP, Brasil. lsrodrigues90@hotmail.com

** Faculdade de Educação Física e Programa de Pós-Graduação em Artes da Cena do Instituto de Artes, Universidade Estadual de Campinas, Campinas, SP, Brasil. roble@fef.unicamp.br a conduta contemporânea como um todo. Esse encontro permitiu descortinar possibilidades para a educação dos sentidos.

Palavras-chave: educação dos sentidos, estética, corpo 


\title{
Education of the senses in the contemporaneity and its pedagogical implications
}

\begin{abstract}
The article explores the "education of the senses", a current yet little explored theme. Although constituting the main form of world perception, as indicated by Michel Onfray, and suffering a sort of overstimulation in the society of information, as posited by Christoph Türcke, the senses are paradoxically directed to objects and specific interests, usually related to consumption. The article presents a reflection about the relationship between body and sensibility, associating the senses' reason with the current logic of "overstimulation". It shows the relevance of the urge for an aesthetic knowledge not directed to art only but to the contemporary conduct as a whole as well. This result revealed new possibilities for the education of the senses.
\end{abstract}

Keywords: education of the senses, aesthetics, body 


\section{Introdução}

A dicotomia entre corpo e mente, que também pode ser traduzida como entre o sensível o inteligível, apresentou nuances diversas ao longo da história, mas sua presença sempre foi marcante na caracterização do pensamento. Talvez seja possível destacar que a suposta superioridade do inteligível sobre o sensível, presente em praticamente todo o percurso, vem sofrendo algum deslocamento a partir de contestações conceituais contemporâneas. Já no século XIX, por meio do abalo nos valores tradicionais, proposto por Schopenhauer e Nietzsche, essa transvaloração passa a ser um projeto possível. 0 corpo ganha visibilidade e até centralidade em alguns argumentos. Toma vulto a ideia de que, afinal, é com o corpo que o humano sente, se expressa e interage.

Notando que o intelectualismo é nitidamente incapaz de captar toda a dimensão sensível da existência, Michel Maffesoli (2005) argumenta pela necessária união entre o sensível e o inteligível, isto é, a experiência sensível à progressão do intelecto. Sua crítica busca descortinar a falta do domínio sensível em nossas vidas, afirmando que a tentativa de impor a razão constitui uma marca da modernidade que a condição pós-moderna pode rever e até mesmo alterar.

Christoph Türcke (2010b) trilha caminho semelhante ao de Maffesoli (2005), ainda que seu olhar seja direcionado a fenômenos mais específicos. De certo modo, podemos inferir que os pressupostos erigidos por Maffesoli corroboram a análise do cotidiano proposta por Türcke. Em tal análise, Türcke (2010b) defende que vivemos em uma sociedade excitada, inquieta, estimulada constante e violentamente pelos meios de comunicação. Observa, porém, que essa estimulação contínua e crescente, ao mesmo tempo é restrita, pois muito especializada. Ela ocorre em choques imagéticos, portanto visuais, por meio de telas e interfaces que nos separam do mundo corporalmente experienciado. Com tal restrição da experiência sensível, ficamos à mercê do racionalismo e do avanço tecnológico desencarnado, algo nomeado por ele como um "trabalho em tela” (Türcke, 2010a). A alternativa que o contemporâneo apresenta é a da conversão da sensibilidade em diversão, sobretudo por meio da torrente de estímulos conduzida pelos interesses mercadológicos e em conjugação com o desenvolvimento da interatividade digital.

No epicentro dessas tensões, entre a tomada de consciência referente à atrofia das experiências sensíveis e a recuperação de tais experiências por meio de uma superestimulação, está a educação dos sentidos que encontramos e, evidentemente, aquela que podemos repensar, propor e estimular. 


\section{Os sentidos na contemporaneidade}

Vivemos em uma sociedade paradoxalmente excitada e anestesiada pela "compulsão à emissão”, explica o filósofo alemão Christoph Türcke (2010b). Tornou-se constante o estado de inquietação, de excitação e de efervescência, principalmente no século XX. Por meio de inúmeros estímulos somos expostos a choques imagéticos e visuais, oriundos especialmente dos meios de comunicação de massa, mergulhando-nos numa tentativa de excitação contínua. Se outrora a palavra "sensação" servia para designar basicamente o estímulo recebido do meio por nosso corpo, hoje ela se converteu em uma espécie de conceito-desejo, no qual o sensacional é profundamente almejado e constantemente produzido.

Sob uma alta pressão de notícias, a propaganda marca o padrão da comunicação com uma lógica da aparição sensacional, experimentação imediata e intensa, seguida de descarte quase instantâneo. A concentração de efeitos audiovisuais no espaço mínimo de tempo representa o desafio estético diante da decadência da imagem tradicionalmente concebida. A propaganda terá sucesso, se for capaz de adiantar algo sobre o prazer que a compra do produto promete. As pressões de custo e de tempo fazem do comercial audiovisual uma espécie de laboratório estético-psicológico-fisiológico das formas comunicacionais mais pregnantes. Não raro, por exemplo, observamos propagandas que fazem uso de associações espúrias ou até explicitamente chocantes, evidenciando uma dinâmica na qual o sentido de realidade é menos importante do que o estímulo agudo. 0 efeito perverso evidente é a dessensibilização do público, o que alimenta uma roda contínua, na qual a nova geração de propagandas vem ainda mais impactante que sua antecedente.

Uma crítica às propagandas como forma de deturpação da realidade ou, até mesmo, de condução das massas não é exatamente uma novidade e, por isso mesmo, não revela qualquer estética que já não tenha sido desnudada, por exemplo, pela escola de Frankfurt, da qual Türcke é, inclusive, um herdeiro. 0 que de novo nos interessa nessa configuração da lógica das sensações reside justamente em aspectos como esses, ilustrados pelo círculo vicioso da estimulação. Tanto nos é possível perceber um dado contemporâneo da educação dos sentidos como notar a importância do corpo nesse processo. Se, em outros momentos, era suficiente expor a falta de uma educação dos sentidos na educação formal e, de modo geral, no mundo que nos rodeia, hoje talvez seja o caso de notar que tal educação está em amplo desenvolvimento, só que pelas mãos dos emissores da sensação e da notícia. 
George Berkeley (1979, citado por Türcke, 2010b) referia-se ao fato de que nós, seres humanos, somos seres sensíveis, inescapavelmente dependentes das sensações que nossos órgãos sensoriais nos transmitem. 0 que não for sensação não existe para nós, pois não podemos compreender o mundo ignorando nossos sentidos; então, o que não é notado, sentido e percebido, simplesmente não é. Para Benjamin (1994), os novos elementos técnicos e a nova arquitetura, a partir da primeira metade do século XX, fortemente moldados pelo ferro e pelo vidro, presentes nas construções físicas das cidades modernas, contribuíram para o aparecimento de um "novo" homem, de uma "nova" sensibilidade. A opacidade do vidro e a impossibilidade de nele deixar as nossas marcas são parte dessa cultura, na qual os homens estariam eliminando seus vestígios sobre a terra. A cidade moderna congrega uma série de transformações que modificam as relações espaço-temporais e entre os sujeitos. Benjamin parece ter adiantado a discussão que a lógica das sensações agora nos impõe. A reprodutibilidade da imagem e o consequente enfraquecimento da aura nos objetos estéticos (Benjamin, 1994) é uma forma de preparação sensorial que permitiu a sociedade da excitação, pois o nível em que ocorrem tais excitações é epidérmico e, como aponta Brissac Peixoto (1996), nada parece mais impertinente do que pedir que as imagens aceleradas de hoje permaneçam. Para Fátima de Paula (1994), a destruição da aura parece ser vista pela estética moderna até mesmo como uma forma de aproximação das massas, uma vez que se direciona univocamente ao presente. A máxima "ser atual” ou seu duplo, “não ser ultrapassado", virou mesmo uma regra da inteligência social, quase uma forma de etiqueta, ainda que possamos perceber o quão imprecisa pode ser uma orientação como essa.

A compulsão à emissão carrega o ambiente de trânsito das sensações. Há demasiados emissores e demasiados estímulos. Para os receptores torna-se difícil a tarefa do discernimento e, paradoxalmente, uma espécie de tédio sensorial faz-se mais comum que a saciedade dos desejos. O homem, como um ser desejante, foi objeto de tratamento no século XIX por meio da obra magna de Arthur Schopenhauer, $O$ mundo como vontade e representação (2005). Nela, o filósofo alemão nos revela a faculdade volitiva como inevitável e avassaladora, levando o homem a emergir em seus desejos infindavelmente. Uma espécie de balança parece ilustrar a forma como Schopenhauer entende a recepção dos estímulos por parte do desejante: se uma vontade tarda a ser saciada, gera-se o desespero (que é um desdobramento angustiado da espera), mas se, por outro lado, as vontades 
são sempre saciadas rapidamente, incorre-se no tédio. É nesse último fenômeno que reside o tédio sensorial da sociedade excitada. A profusão exagerada dos estímulos não permite tempo suficiente para que a vontade possa se processar de modo satisfatório, fazendo saciar-se qualquer vontade emergente com a maior brevidade possível. Tal como podemos encontrar uma pessoa que escreva o suficiente para se enquadrar como alfabetizada, mas não possua proficiência, de fato, na linguagem escrita, ou quem tenha acesso regular a alimentos, mas, pela falta de correto equilíbrio nessa alimentação, possa ser considerado malnutrido, em termos de uma educação dos sentidos podemos encontrar atualmente seres dessensibilizados, imersos num caldo denso de estímulos sensoriais. Não se trata, portanto, de simplesmente abrir a porta dos sentidos, mas de uma operação fundamentalmente de discernimento - em suma, de um processo de educação.

Pequenas considerações sobre os cinco sentidos humanos

Sou um guardador de rebanhos,

0 rebanho é os meus pensamentos

E os meus pensamentos são todos sensações.

Penso com os olhos e com os ouvidos

E com as mãos e os pés

E com o nariz e a boca.

Pensar uma flor é vê-la e cheirá-la

E comer um fruto é saber-lhe o sentido.

Por isso quando num dia de calor

Me sinto triste de gozá-lo tanto,

E me deito ao comprido na erva,

E fecho os olhos quentes,

Sinto todo o meu corpo deitado na realidade,

Sei a verdade e sou feliz.

Fernando Pessoa (1986a)

Uma extensa discussão filosófica pode ser retomada, se desejarmos abordar a questão do conhecimento a partir da percepção ou a partir da razão. Mesmo no 
que diz respeito ao conhecimento sensível, há correntes significativamente variadas no entendimento de como a sensação (e, em outras correntes, a percepção) opera epistemologicamente. Ainda que tal discussão se articule com nossos propósitos, optamos, neste texto, por um relevo mais evidente na discussão filosófica com projeções educacionais, o que nos orienta mais a pensar nos sentidos humanos como elementos de potência no processo educativo, e não tanto em discutir a origem do conhecimento. Ao destacarmos as relações entre os cinco sentidos e a educação na contemporaneidade, colocamo-nos em um território inferencial, no qual as premissas são as formas de relação entre os sentidos e a realidade, e nossas conclusões, interpretações abertas à reflexão.

Para Aldous Huxley (2009), nossa educação predominantemente verbal desconsidera que a experiência dos sentidos possa abrir as portas da percepção. Encontramos potência no processo educativo por meio dos sentidos, uma vez que a experiência é imprescindível nesse contexto. A abstração, cara à tradição racionalista, aparta o sujeito pensante do objeto, não carece da experiência e, assim, edifica modelos de compreensão que abdicam da educação dos sentidos. À medida que uma possível inversão metodológica se proponha, ou seja, que a experiência dos sentidos ocupe um papel protagonista na ação educativa, nos é possível inferir que uma formação distinta e menos racionalista possa ocorrer. Evidentemente, essa noção de protagonismo na experiência sensorial não corresponde a anular o papel do raciocínio abstrato, mas a propor outras vias. Por essas razões, parece-nos possível pensar que o processo educativo dos sentidos possa gerar uma nova potência, ou seja, uma outra disposição de forças, que se origina na experiência da visão, da audição, do tato, do olfato e do paladar.

Nesse percurso de relação entre os sentidos e a realidade, destaque evidente encontramos na visão. Sentido humano por excelência, a visão ocupa uma posição muito mais elevada na hierarquia dos sentidos, quando comparada aos demais sentidos. Se a história do homem corresponde, em grande medida, a uma genealogia da moral (Nietzsche, 2004), o sentido humano por excelência deve ter, de muitos modos, se envolvido com essa moral. "Enxergar mais distante", "ser uma pessoa de visão", "não estar enxergando o que está acontecendo", entre muitas outras assertivas de cunho moral, aderiram-se à visão de tal modo, que não seria exagerado pensarmos em uma espécie de hegemonia da visão, em detrimento dos demais sentidos ou de uma totalidade sensorial. Por um lado, a criança vive um cotidiano de muitas ima- 
gens, aceleradas e sem permanência; por outro, recebe uma educação econômica e moral do olhar, na qual o objeto da visão ou os procedimentos do olhar são, frequentemente, mais importantes do que uma visão contemplativa, extensa e subjetiva. A pintora Georgia O`Keeffe (citada em Ackerman, 1996) afirma que “de certa maneira, ninguém vê realmente uma flor; é tão pequena, não temos tempo - e ver leva tempo" (p. 319). A economia do olhar parece operar, de partida e fundamentalmente, economia de tempo e espaço.

Parece que, para uma profunda educação da visão, é preciso, primeiramente, querer olhar, ter prazer em olhar e não apenas constatar o que se viu. Experiência estética e registro são, nesse caso, bastante diferentes. No mais, parecem existir diversas formas de ver, mesmo sem os olhos, relembrando, imaginando, sonhando. É relevante, então, fazer dialogar suas visões, apreendendo o que cada uma delas tem para ensinar a outra.

Já o olfato, no extremo oposto da valoração moral, costuma ser associado aos procedimentos animais, pois exige proximidade, movimentos supostamente deselegantes das narinas e um comportamento mais ativo. A distância que a visão permite não persiste no olfato humano. Contudo, sua relação com a memória é especialmente destacável. Percebemos um aroma e frequentemente somos levados a lembranças. Podemos detectar mais de dez mil odores diferentes. Nosso olfato é extremamente preciso, mesmo que seja muito difícil descrever um cheiro para alguém que nunca o sentiu antes. Trata-se de um sentido mudo. Os odores são coisas íntimas e, mesmo assim, não conseguimos lembrar seus nomes, então temos a tendência de descrever o que nos fazem sentir, como por exemplo, alguma coisa "cheira agradável" ou "tem um odor repugnante".

Quanto ao paladar, muitas vezes, aparece como o mais tentador, mas também como aquele para o qual se direcionam restrições severas, oriundas de toda sorte de dietética e da obsessão contemporânea pela forma física, fundamentalmente do corpo magro. 0 olfato se imbrica com o paladar, o sabor de um alimento inclui textura, cheiro, temperatura, cor e, até mesmo, os ruídos sonoros provocados na mastigação. Assim, culinária e desenvolvimento do paladar podem ser parceiros de uma mesma educação dos sentidos, se o foco for o dos sabores e não o da receita.

A audição parece ter sido reduzida ao hábito de escutar instruções, detectar o mínimo suficiente para realizar a ação. Ao mesmo tempo, na educação formal, 
um desespero de docentes é o de não serem ouvidos. Educar a audição não é somente uma educação musical ou o silêncio respeitoso. Também se trata de oferecer muitos estímulos, e mais, oferecê-los, ao menos às vezes, isoladamente, pois os dados auditivos muito frequentemente estão acompanhados de estímulos visuais que "roubam" a sensação mais singular da audição. Separar a audição e concentrar-se nela é tarefa educativa das mais sérias e revolucionárias em uma cultura extremamente visual.

John Cage (citado em Ackerman, 1996) declara a inexistência do silêncio: mesmo que não ouçamos o mundo lá fora, ouvimos o sussurrar, as palpitações, o latejar de nossos corpos, os possíveis zumbidos ou estalos. Mesmo pessoas surdas relatam grande variedade de sons que sentem. É tácito afirmar que a maioria das pessoas, se tivesse que escolher entre a audição ou a visão, provavelmente optaria por preservar a visão; contudo, é provocante a leitura de Ackerman (1996), quando o autor cita o famoso exemplo de Helen Keller:

Sou tão surda quanto cega. Os problemas da surdez são mais profundos e complexos, senão mais importantes, do que os da cegueira. A surdez representa desgraça muito pior, pois significa a perda do estímulo mais vital - o som da voz que nos traz a linguagem, que agita os pensamentos e permite que permaneçamos na companhia intelectual do homem. (p. 233) 1

Por fim, o tato. Para Caruso (2009), ajuda o cérebro na identificação e na percepção fundamental de nós mesmos, das outras pessoas e de tudo que está a nossa volta. As mãos são nossas aliadas na percepção e no fazer diário, trabaIham nas coisas mais funcionais e simples. É comum a associação direta e exclusiva entre o toque e o tato, fato que empobrece a dimensão desse sentido. 0 toque é uma ação dotada de significação que extrapola o tato; em contrapartida, o tato compreende muitos outros fenômenos que não apenas o toque. Mais uma vez estamos diante de uma instrumentalização dos sentidos, nesse caso representada pela atrofia do senso tátil, ou mesmo pela incompreensão de sua dimensão na totalidade do corpo. Uma educação do corpo pode propor essa compreensão menos setorizada e instrumental, revelando potências e ampliando as possibilidades táteis do ser humano. Tal ins-

1. Trechos extraídos de uma carta escrita ao Dr. J. Kerr Love, em 31 de março de 1910, do programa de comemoração à visita de Helen Keller a Queensland Adult Deaf e Dumb Mission, em 1948. 
trumentalização parece ter como pano de fundo a racionalização do corpo e da conduta humana, na medida em que vê, na função pragmática da ação, a única razão para a manifestação sensorial. Dito de outro modo, os sentidos parecem ter perdido a sua autonomia, tornando-se meros facilitadores na racionalização da existência. Assim como nos sentidos não visuais, o tato experimentou ainda o peso moral de sua associação com atitudes carnais desaprovadas pela tradição judaico-cristã, o que alarga consideravelmente a supressão sistemática de sua prática, construindo corpos com "isolamentos táteis" e uma conduta corporal de repulsa oriunda dessa construção.

Essas pequenas notas sobre os sentidos não têm a intenção de construir um panorama descritivo de sua práxis, tampouco uma ética da sensibilidade humana. Ao revelarmos os contornos mais evidentes dessa atrofia e instrumentalização dos sentidos, apenas construímos uma base argumentativa introdutória que nos permite evidenciar as carências e os limites que se colocam como premissas, ao se pensar numa educação dos sentidos. Uma educação estética, em seu amplo alcance, dobra-se sobre as potencialidades sensoriais, na medida em que dos sentidos parte e para eles retorna. Assim, cabe-nos talvez avançar no campo propositivo, absorvendo aquilo que certas correntes do pensamento atual vêm convencionando como uma "razão sensível".

\section{A busca por uma razão sensivel}

Creio no mundo como num malmequer,

Porque o vejo. Mas não penso nele

Porque pensar é não compreender...

o Mundo não se fez para pensarmos nele

(Pensar é estar doente dos olhos)

Mas para olharmos para ele e estarmos de acordo...

Eu não tenho filosofia: tenho sentidos....

Fernando Pessoa (1986b)

Para Maffesoli (1996), a sociedade não é apenas um sistema mecânico de relações econômico-políticas ou sociais, mas um conjunto de relações interativas, feito de afetos, emoções, sensações que constituem o corpo social, um conjunto sobre um movimento irreprimível de atrações e repulsões. Essa temática da 
"atração" chamou atenção de P. Tacussel (citado por Maffesoli, 1996), filósofo que argumenta que as diversas agregações sociais vão além das causalidades racionais. É possível observar um desejo de “estar-junto", o qual integra boa dose de sensibilidade e participação de todos os sentidos (visual, olfativo, tátil, auditivo e gustativo). Mesmo envolvendo agregações predominantemente inconscientes, não deixa de ser um fenômeno social relevante a ser debatido, em especial se temos como objetivo final um discurso sobre educação.

Ainda com esse autor, podemos dizer que a sensação compreendida num conjunto é fator de relação social, pois um elemento analisado separadamente pode remeter a uma sensação menos agradável do que a impressão do conjunto. Essa afirmação explica como a sensação de frio pode se tornar agradável, quando aliado à prática, por exemplo, de um lazer de inverno. No conjunto, há a sensação de bem-estar e de um bem-estar-junto (Maffesoli, 1996).

Türcke (2010b) afirma que as sensações estão a ponto de se tornar as marcas de orientação da vida social como um todo. Nesse mesmo sentido, Maffesoli (1996) argumenta que o sensível não pode mais ser considerado um fator secundário na construção da realidade social. Numerosos são os indícios que acentuam seu aspecto essencial, por isso é preciso considerar o sensível como elemento central no ato de conhecimento. Claro que, em ambos os autores, fica explícita a percepção de que a origem dos estímulos sensoriais está dispersa pelas mídias de nosso tempo, que não são organizadas por uma intencionalidade educativa. Talvez seja preciso propor um conhecimento contrário ao monopólio cognitivo da razão, um esforço que repouse sobre a consideração do sensível e reconheça as sensações em ação na vida social. Cabe lembrar que isso não significa negar a razão, mas, sim, enriquecê-la. Para elaborar uma verdadeira “razão sensível”, é preciso buscar a lógica interna que move as coisas e as pessoas, reconhecer a parcela de imaginário que as impregna, levando em conta o “dado", reconhecendo-o como tal e respeitando suas coibições (Maffesoli, 1996). Diane Ackerman (1996), poeta e cientista, argumenta que não existe maneira de compreender o mundo, sem antes detectá-lo por meio de nossos sentidos, numa perspectiva muito próxima da de Onfray (1999), quando este afirma que "a máquina racional se põe em movimento quando tudo já está feito, quando o corpo já falou” (p.53). É possível aprimorar nossos sentidos com a ajuda de microscópios, telescópios, aparelhos de audição, sensores de movimento, cromatógrafos e toda uma sorte 
de máquinas que mimetizam as potencialidades sensoriais. Mas não é possível, com eles, capturar o todo fenomênico que somente os sentidos humanos, na imanência corporal do homem, são capazes de conceber. Ackerman (1996) nos aponta ainda que, para começarmos a compreender o que é a consciência, precisamos tentar entender os sentidos e a forma como esses vêm se transformando historicamente, como podem ser aguçados, quais são seus limites, com relação a quais temos tabus arraigados e o que nos podem ensinar sobre o mundo em que habitamos, numa perspectiva não racionalizante, pois “as últimas descobertas da fisiologia sugerem que a mente não se encontra exatamente no cérebro, mas percorre o corpo em caravanas de hormônios e enzimas, ocupadas em dar sentido às maravilhas que catalogamos como tato, paladar, olfato, audição e visão" (p. 19).

Uma razão sensível, em suma, não despreza a racionalidade e compreende a capacidade lógica humana como um fator essencial a seu desenvolvimento cognitivo e social; contudo, nota a incapacidade de isolar o dado racional do dado sensível, assumindo a ação humana como uma amálgama inevitável desses fenômenos equivocadamente alocados em setores distintos de nossa existência. É nesse sentido que uma razão sensível parece conclamar a educação pela e para sensibilidade. Não se trata, portanto, de uma perspectiva de substituição, mas de uma conjugação já tardia das capacidades humanas em sua totalidade e, quem sabe até, numa perspectiva futura, da compreensão mais visceral de sua indissociabilidade fenomênica.

\section{Pontos de convergência:}

\section{a possibilidade pedagógica da experiência estética}

Uma vez que as premissas de nossos argumentos foram colocadas em torno da importância dos sentidos humanos na produção do conhecimento e que tal opção não deve incorrer nem em instrumentalização, nem em superestimulação vazia, resta-nos inferir quais possibilidades se colocam para uma educação dos sentidos. Que formas de educação estética podem ser capazes de colocar em atividade as possibilidades sensoriais? Que razão decorre dessa opção? Qual é o papel efetivo do corpo nessa educação? Evidentemente as respostas são amplas e excedem em muito nossos limites neste texto. Contudo, à guisa de inferências, podemos encontrar pontos de convergência, nos quais a educação dos sentidos seja praticamente uma imanência, pois não se configura como uma sistemática 
educativa, mas, antes, uma manifestação estética. Trata-se, portanto, de requisitar o dado sensível não para ilustrar o conhecimento, mas para ele próprio ser o gerador do conhecimento, dada a sua inteireza, sua integridade com o humano, tal como lemos em Benjamin (1994), para o qual a percepção sensível é, ao mesmo tempo, histórica, uma vez que a percepção, os sentidos e as sensibilidades são educados e educáveis, expondo uma relação intensa entre sujeito e objeto, na qual não é possível pensarmos em apreciação vazia.

Um exemplo que trazemos para o desdobramento dessas considerações é a obra da artista plástica brasileira Lygia Clark (1920-1988). Suas experiências sensoriais no campo da "comunicação gestual" e os objetos de arte produzidos por ela expõem uma amálgama entre sensibilidade, razão, cultura, arte e educação. 0 corpo é elemento central nessas obras, e seu alcance estético não se encarcera no produto artístico ensimesmado, de certa forma corroborando a sua posição autointitulada de “não-artista”. Com isso não se formula uma crítica rasa à arte, mas se amplia o conceito de estética a uma razão como vínhamos ensaiando, o que exibe um exemplo desse ponto de convergência talvez muito profícuo para a educação dos sentidos.

Por meio de uma crítica à forma como vivemos na modernidade, inseridos em um mundo midiático no qual trabalhamos, convivemos e nos divertimos, em telas que nos dizem o que fazer e nos guiam aonde queremos chegar, Clark propõe uma arte a serviço da libertação do ser humano por meio do seu corpo, gesto e sensibilidade. Lygia Clark colocou o objeto da arte na mão de seu interlocutor e estabeleceu que a "arte é o seu ato". Fundou a arte participativa e compartilhada desde então, destravou as portas do inconsciente e propunha isso como manifestação artística transcendental. Objetos sensoriais e relacionais, entre muitos outros artefatos, abriam um canal direto com o primitivo interior, criando um estado de autoconhecimento revelador e, por isso, libertador.

Entre 1966 e 1968, Clark estabelece um vínculo com a vida dos sentidos e cria os objetos sensoriais, os quais são objetos de nosso cotidiano, como sacos plásticos cheios de ar, água, areia ou isopor, tubos de borracha, canos de papelão, panos, meias, conchas, mel, entre muitos outros. Esses objetos estimulam de várias formas os diversos sentidos dos participantes, e sua intenção com isso é desvincular o lugar do espectador e aproximá-lo de um estado onde o mundo se molda, passando a ser constante transformação.

2. Disciplina que Lygia Clark ministrou na Sorbone em 1972. 


\section{Figura 1: Óculos}

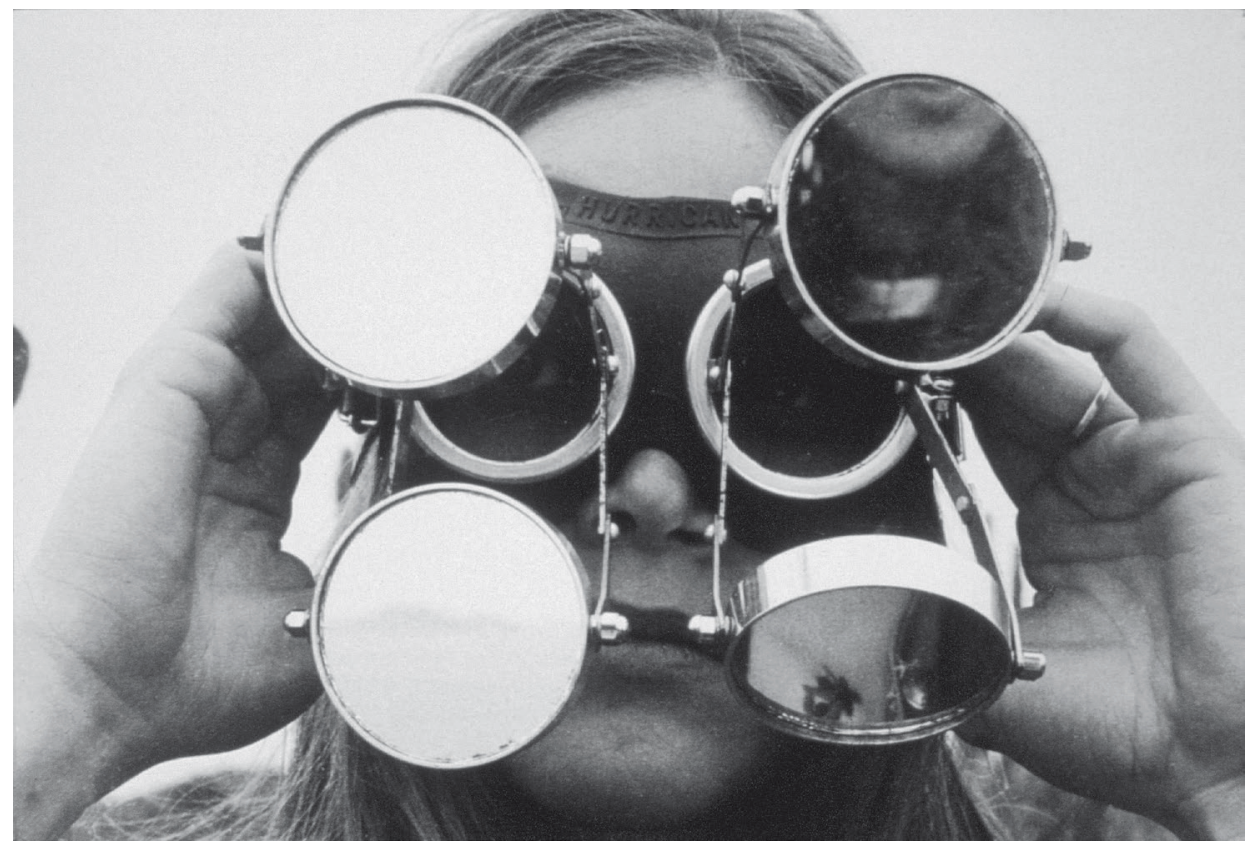

Fonte: LYGIA CLARK - “Óculos”, 1968 - Ref. 20033; Fotógrafo Desconhecido.

\section{Figura 2: Luvas Sensoriais ${ }^{4}$}

Fonte: LYGIA CLARK - “Luvas Sensoriais”, 1967 Ref. 20064; Fotógrafo Desconhecido.

3. Óculos (de mergulho, adaptado) unidos a peças metálicas dobráveis, formando um conjunto que se estira e se contrai. Unida transversalmente às peças metálicas, uma haste de metal sustenta dois espelhos circulares de dupla face. A haste se converte em eixo para o movimento de rotação dos espelhos, e sua prolongação até o exterior do conjunto funciona como peça de manipulação para 0 participante. Os quatro espelhos fragmentam a percepção visual do espaço circundante. Agradecimento: Associação Cultural "O Mundo de Lygia Clark".

4. Luvas de diversos materiais e tamanhos. Bolas de distintas dimensões e texturas. Os participantes pegam as bolas com as mãos, usando luvas e com as mãos nuas; assim, são obrigados a redescobrir o tato. Agradecimento: Associação Cultural "0 Mundo de Lygia Clark”.

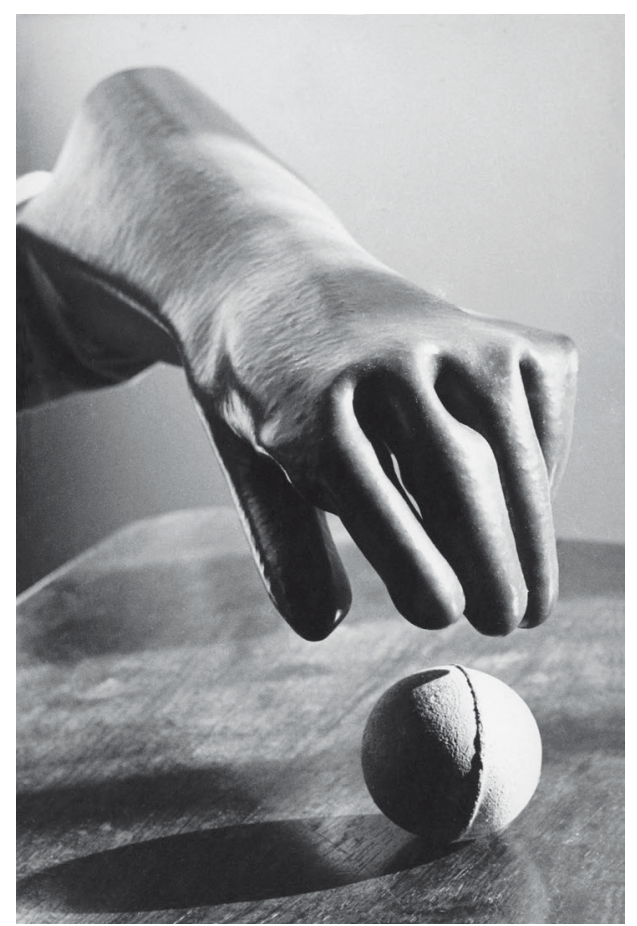




\section{Figura 3: Máscaras Sensoriais ${ }^{5}$}

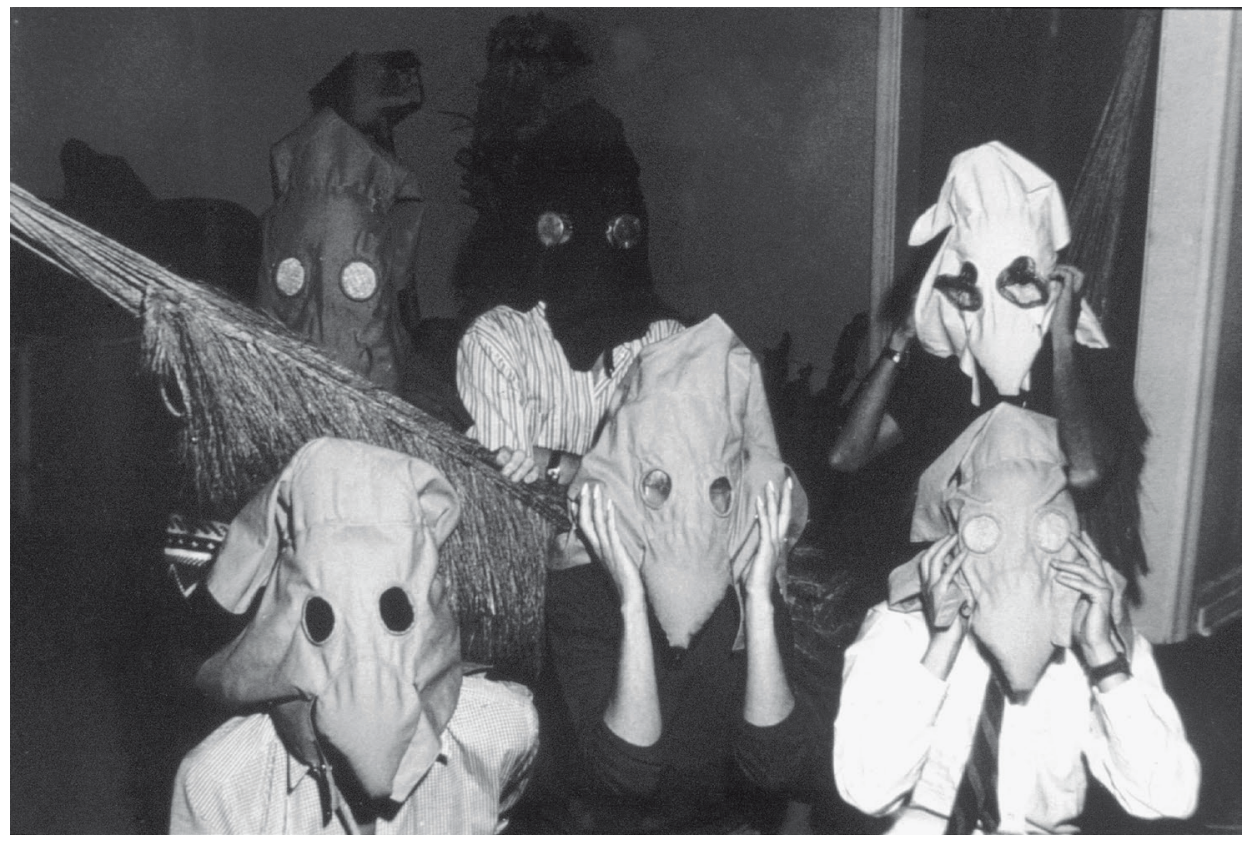

Fonte: LYGIA CLARK - “Máscaras Sensoriais”, 1967 - Ref. 20409; Fotógrafo Desconhecido.

As propostas de Lygia Clark são do campo da arte e não se constituem como projetos educativos em sentido estrito. Contudo, uma vez que a artista elegeu o sensorial como um dos focos de suas intervenções, acabou por descortinar experiências que, indiretamente, iluminam possíveis intervenções educativas. As instalações, os materiais e o universo estético por ela elaborado parecem inspiradores para propostas em sentido educativo, uma vez que operam uma espécie de flexibilização no fluxo tradicional do conhecimento, ou seja, parece haver um jogo intermitente entre o conhecimento sensorial e racional, quer pela experiência da obra em si, quer pelas escolhas artísticas adjacentes. Em um ambiente educativo, podemos imaginar como proveitosa a alternativa de apresentação dessas obras ou, até mesmo, como desafios de reconstrução, experimentação e reinvenção. Os trabalhos de Clark parecem laboratórios sensoriais, apontando possibilidades para alternativas pedagógicas na educação dos sentidos.

5. Máscaras idênticas feitas de tecidos, que só variam pelos estímulos sensoriais que as caracterizam e as cores que as designam. As máscaras têm cheiros distintos, dispositivos especiais que alteram a audição e uma espécie de óculos com perspectivas visuais diversas, segundo 0 projeto de cada máscara. 0 participante, ao pôr a máscara, experimenta sensações novas, que oscilam desde a integração ao mundo que o rodeia até uma interiorização que chega ao isolamento absoluto. Agradecimento: Associação Cultural “0 Mundo de Lygia Clark”. 
Redescobrindo a dimensão sensível do educar por meio de pontos de convergência inspirados em experiências estéticas como as de Lygia Clark, tomando o corpo e suas potencialidades sensíveis e expressivas como ponto de partida para a descoberta e a reinvenção da prática educativa, talvez possamos nos reconciliar com a raiz grega da palavra estética (aisthesis), indicativa da capacidade do ser humano de sentir a si próprio e ao mundo num todo integrado.

Marcelo Pereira (2010) elucida que a experiência estética indica uma diferença de caráter qualitativo em relação à experiência cotidiana ou em geral, sendo uma experiência extracotidiana. Não necessariamente prazerosa, porquanto sensível, é uma experiência que não se encerra em si mesma, propõe o pensamento, via sensibilidade, em outro nível de compreensão, de entendimento. De acordo com Gumbrecht (2006, p. 54, citado em Pereira, 2010), os conteúdos da experiência estética compreendem "os sentimentos íntimos, as impressões e as imagens produzidas pela nossa consciência”, os objetos são "as coisas suscetíveis de desencadear tais sentimentos, impressões e imagens", as condições seriam caracterizadas pelas "circunstâncias situacionais historicamente específicas nas quais estaria baseada" e os efeitos da experiência estética são "as consequências e as transformações decorrentes" dessa espécie de experiência (p. 560).

A educação estética na escola, para Márcia Strazzacappa, Sílvia Schroeder e Jorge Schroeder (2005), ocorre desde o momento em que o aluno entra no espaço escolar - os muros, os portões, os jardins, as paredes, os murais com seus quadros de avisos, os corredores, a qualidade de imagens que preenchem cada sala de aula, entre outros. Isso tudo influencia na formação estética daqueles que aí conviverão, de acordo com a forma de relação entre professores, alunos e funcionários com esse ambiente acolhedor ou não. A educação estética não está relacionada somente a cores, texturas e formas, mas também a linguagens como a música, a dança, o teatro, por exemplo, que também são responsáveis por uma educação do sensível no plano mais sistemático da arte. Como já dito anteriormente, não se trata de discutir detalhadamente a experiência estética como sinônimo ou não de experiência artística, mas é inescapável perceber que esta segunda se apresenta como um espaço privilegiado de vivência da primeira.

Comumente, a experiência artística está ligada a processos específicos das linguagens da arte, tais como a música, o teatro, a dança, a pintura, entre outras. Já a experiência estética seria um contato com a beleza em sua forma ampla, organizada 
ou não em uma linguagem. A natureza, por exemplo, pode oferecer uma experiência estética no contato do sujeito com sua beleza, ainda que não possamos considerá-la um produto artístico. Evidentemente, esse é um terreno arenoso, uma vez que pensadores distintos chegaram a conclusões diferentes sobre essas relações nas quais arte e estética se interpenetram todo o tempo. Para Dewey (2005), por exemplo, em que pesem distinções formais como as que apontamos acima, a arte é sempre uma experiência da beleza, e isso é mais relevante do que seus contornos técnicos. Nesse sentido, não haveria razão para diferenciar a experiência estética da artística, ambas ancoradas no conhecimento sensível.

O assunto não é de menor envergadura no que tange a um epistemologia prática, mas a confluência que parece bastar para os limites de nosso argumento é aquela que distingue a forma de produção de conhecimento que o estímulo à educação dos sentidos parece incentivar. Essa forma nos aparece como a do incremento do conhecimento sensível em contraposição aos modelos racionalistas puramente abstratos. Por esse caminho, interessa-nos, por ora, a alocação da educação dos sentidos na confluência do conhecimento sensível, na qual as experiências, sejam elas estéticas, artísticas ou uma amálgama de ambas, constituem uma alternativa ao abstracionismo da razão desencarnada.

Ainda para Strazzacappa, Schroeder e Schroeder (2007), para uma educação do sensível não é o simples contato esporádico com algumas obras, nem a mera estimulação sensorial, que fará com que se "desperte" uma sensibilidade para as diversas linguagens. Além do fato de elas só existirem numa interação social, há a necessidade de "se apropriar de", presente no fazer, experimentar, arriscar, testar, em todas as atividades inerentes à criação, em termos de uma experiência artística, especialmente quando se toma essa experiência como projeto educativo. Por isso, mais uma vez nos parece exemplar citar as experiências do conhecimento sensível como uma porta de muitas possibilidades para essa proposta de educação dos sentidos. Em complemento, constatamos a necessidade de uma prática constante de tais experiências, de modo a produzir uma incorporação desses estímulos, numa efetividade das possibilidades pedagógicas.

Uma educação dos sentidos não é uma proposta nova nem inovadora. Talvez, até mesmo, possamos pensar em tempos passados, nos quais a presença de estímulos sensoriais foi, de modo intencional ou espontâneo, algo muito mais presente na educação em sentido amplo. A título de exemplo, situando a relação entre educação e 
infância, podemos lembrar Steinberg e Kincheloe (2001), autores que apontam para o desenvolvimento de uma "cultura infantil" fortemente atrelada aos interesses do consumo e, por essa razão, pouco interessada em experiências exploratórias ou sensoriais. Mais especificamente, para os autores, parece que os desejos e os sentidos não são mais construídos pela experiência e, sim, conduzidos intencionalmente pelas corporações comerciais, dispostas a determinar o sentido das sensações, sempre harmônico com as promessas dos produtos voltados à criança. Em tal contexto, a sutileza das descobertas sensoriais pela experiência cotidiana talvez seja frequentemente atropelada pela determinação das sensibilidades. Mas estes mesmos autores acreditam que possam ser criadas estratégias de resistência que se situem na relação entre pedagogia, produção de conhecimento e desejo. Não apontam explicitamente a educação dos sentidos como uma dessas estratégias possíveis, mas nós, pelo exposto, deduzimos que esse raciocínio complementar talvez se configure como uma hipótese viável.

A polaridade que encontramos hoje nesse cenário, tendo, de um lado, procedimentos pedagógicos de um racionalismo asséptico e, no outro polo, a superestimulação sensorial da "sociedade do espetáculo" (Debord, 1997), desestabiliza a permanência de uma efetiva educação dos sentidos. Por essa razão, talvez possamos creditar, nos pontos de convergência expostos, a possibilidade de uma retomada desse esforço pelo conhecimento sensível no contexto da educação.

Evidentemente, nosso texto e as considerações que se enumeram pelos nossos argumentos não possuem a intenção de esgotar o assunto, tampouco desconsiderar quão arenoso é o terreno dessa discussão. Dado o cenário bastante disperso sobre o tema, no que concerne tanto ao seu tratamento teórico sistemático quanto às suas irradiações práticas, propomos tais reflexões como um pequeno esforço de lançar luz ao problema, enumerando alertas urgentes como nas considerações de Türcke (2010b), mas encontrando também sinais nutritivos de resistência, exemplificados aqui pela razão sensível de Maffesoli ou pelo contato com os objetos sensoriais de Lygia Clark. Ao apresentarmos essas alternativas, não configuramos esforços pragmáticos, mas nos mantemos no plano mais espraiado da educação em sentido geral. Mais implicações pedagógicas precisam ser traçadas, e está em nosso horizonte tal continuidade que os pressupostos aqui engendrados inauguram. Talvez possamos dizer que, ao nosso modo, tateamos também o conhecimento sensível, em pistas que expressaram reflexões e textos, por meio dos quais acreditamos em uma educação mais encarnada e corpórea. 


\section{Referências bibliográficas}

Ackerman, D. (1996). Uma história natural dos sentidos. (2a ed.). Rio de Janeiro: Bertrand Brasil.

Benjamin, W. (1994). Obras escolhidas VI - magia e técnica, arte e política. (7a ed.). São Paulo: Brasiliense.

Caruso, C. (2009). Almanaque dos sentidos. São Paulo: Moderna.

Debord, G. (1997). A sociedade do espetáculo. Rio de Janeiro: Contraponto.

Dewey, J. (2005). Art as experience. Penguin Group: New York.

Gumbrecht, H. U. (2006). Pequenas crises: experiência estética nos mundos cotidianos. In C.

Guimarães, B. S. Leal, \& C. Mendonça (Org.), Comunicação e experiência estética. Belo Horizonte: Editora UFMG.

Huxley, A. (2009). The doors of perception. New York: Harper Collins.

Maffesoli, M. (1996). No fundo das aparências (2a ed.). Petrópolis: Vozes.

Maffesoli, M. (2005). Elogio da razão sensível. Petrópolis: Vozes.

Nietzsche, F. (2004). Genealogia da moral. São Paulo: Companhia das Letras.

Onfray, M. (1999). A arte de ter prazer. São Paulo: Martins Fontes.

Paula, F. (1994, 1ํ semestre). Tensões e ambiguidades em Walter Benjamin: a modernidade em questão. Plural, 1, 106-130.

Peixoto, N. B. (1996). Paisagens urbanas. São Paulo: Ed. Senac.

Pereira, M. de A. (2010, setembro/dezembro). A dimensão performativa do gesto na prática docente. Revista Brasileira de Educação, 15(45), 555-563.

Pessoa, F. (1986a). O guardador de rebanho II. In F. Pessoa, Obra poética e em prosa. Porto: Ed. Antonio Quadros.

Pessoa, F. (1986b). O guardador de rebanho IX. In F. Pessoa, Obra poética e em prosa. Porto: Ed. Antonio Quadros.

Schopenhauer, A. (2005). O mundo como vontade e representação. São Paulo: Ed. Unesp.

Steinberg, S, \& Kincheloe, J. (2001). Cultura infantil: a construção corporativa da infância. Rio de Janeiro: Civilização Brasileira.

Strazzacappa, M., Schroeder, J., \& Schroeder, S. (2007). A construção do conhecimento em arte. In A. Bittencourt, Gestão, currículo e cultura (Vol. 1). Campinas: Faculdade de Educação. 
Tacussel, P. (1984). L'attraction sociale. Paris: Méridiens; Klincksieck.

Türcke, C. (2010a, 4 a 17 outubro). Sob a mira da metralhadora audiovisual. Jornal da Unicamp. Campinas, pp. 6-7.

Türcke, C. (2010b). Sociedade excitada - filosofia da sensação (1a ed.). Campinas: Ed. Unicamp.

Submetido à avaliação em 8 de novembro de 2013; aprovado para publicação em 9 de dezembro de 2014. 